\title{
DE OVERBRENGING VAN DE BANAAN EN DE BACOVE UIT AFRIKA NAAR TROPISCH AMERIKA IN HET BEGIN VAN DE 16DE EEUW
}

\author{
DOOR
}

JHR. L. C. VAN PANHUYS

Te Ahrensburg in Holstein woont de oud-majoor van het Duitsche leger, dr. Georg Friederici, wiens naam (met een kleine verandering van spelling) niet onbekend is in de geschiedenis van Suriname. Thans eere-doctor van de Amsterdamsche universiteit, heeft hij zich al veel vroeger, als jong doctor, als een uitstekend taalgeleerde, als een degelijk beoefenaar van de volkenkunde van Nederlandsch-(Oost-)Indië, met name ook als een onderzoeker van in Indië voorkomende talstelsels, doen kennen. Maar vooral heeft hij studie gemaakt van de primitieve volken van de Nieuwe Wereld. In het begin van dit jaar, op een bijeenkomst van ethnologen in het Koninklijk Koloniaal Instituut te Amsterdam noemde dr. Fahrenfort van de Amsterdamsche universiteit hem de beste Amerikanist, dien wij hebben.

Uitkomsten van zijn onderzoekingen mogen belangrijk en betrouwbaar worden genoemd. Beknopt en duidelijk geeft hij de in mijn titel vermelde oplossing van een vraagstuk, waarover vele geleerden het geruimen tijd oneens zijn geweest. Hij doet dit onder den titel Lehnwörter exotischer Herkunft in europäischen Sprachen op blz. 139 tot en met 155 van den jaargang 1934 van het te Jena en te Leipzig door W. Gronau uitgegeven, door de hoogleeraren Gamillscheg (Berlijn) en Winkler (Weenen) bewerkte Zeitschrift für französische Sprache und Literatur, Band LVIII, Heft 3 en 4.

Zijn uitspraak is thans, na een tijdperk van onzekerheid, van meeningsverschil, dat al van Alexander von Humboldt af, over A. de Candolle, tot de allerlaatste tijden toe dagteekende, definitief. Ze luidt, dat de geschiedenis van de Musa-plant en van den naam van de plant neerkomt op het volgende (men houde bij die uitspraak in het oog, dat de botanische Latijnsche naam van musa 
geldt zoowel voor de bacove als voor de banaan, welke twee musavariëteiten in plantkundig opzicht weinig van elkander schijnen te verschillen):

De uit de Oude Wereld stammende plant werd door de Portugeezen en de Spanjaarden, kort na de ontdekking van het westelijk vastland, van Afrika uit naar Amerika overgebracht. De Portugeezen transporteerden ze onder den naam $\mathrm{b}$ a $\mathrm{n}$ a $\mathrm{n}$ a van Guinea, onder den naam $\mathrm{p}$ a c o b a van Angola naar Brazilie. De Spanjaarden gaven hun oud woord $\mathrm{pl}$ a $\mathrm{t}$ a $\mathrm{n}$ o aan de nieuwe plant en voerden ze onder die benaming in hunne bezittingen in Amerika in.

Zooals gewoonlijk het geval is bij dergelijke moeilijke vragen op het gebied van de plantkundige aardrijkskunde, heeft de taalkunde de uiteindelijke, nu vaststaande en hierboven cursief aangegeven oplossing gebracht, en het is, zooals gezegd, dr. Friederici, die deze heeft gevonden.

Terecht zegt hij, dat het voor een taalonderzoeker, die niet tegelijk Amerikanist of Oriëntalist is, en die zich niet voor het minst gedurende geruimen tijd grondig met de desbetreffende litteratuur heeft beziggehouden, alles behalve gemakkelijk is om een artikel over de afkomst, de aanvaarding en de spraakkunstige ontwikkeling van exotische geleende woorden in Europeesche talen te schrijven. Een niet geheel en al deskundig onderzoeker is min of meer aangewezen op bronnen uit de tweede hand, en, doordat hij de oorspronkelijke berichten niet kent, grijpt hij naar vertalingen en overzichten en stelt zich ieder oogenblik bloot aan het gevaar zich te vergissen, omdat de vertalers en overzicht-vervaardigers fouten kunnen hebben gemaakt, wat zij in dit geval menigmaal hebben gedaan. Dr. F. wijst op fouten, door den hoogleeraar professor R. Loewe in een artikel in het Zeitschrift für vergleichende Sprachforschung van 1933 begaan; hij toont aan dat prof. L. verkeerd deed door blindelings artikelen tot grondslag te nemen uit de groote New English Dictionary, die door den verdienstelijken John Murray is uitgegeven. In plaats van de door Filippo Pigafetta in 1591 te Rome uitgegeven „Relazione del Reame di Congo" bezigde prof. L. helaas een slechte Latijnsche vertaling van 1624 , een vertaling, waarin de vertaler van 1624 een toevoeging aanbracht, waardoor de tekst van 1591 werd vervalscht. Daardoor werden door prof. L. daarop gebouwde veronderstellingen op het gebied van taal en kunstgeschiedenis waardeloos. Wil men het geschil in alle bijzonderheden nagaan, dan dient men niet alleen het Nederlandsch, Fransch, Duitsch en En- 
gelsch maar ook het Italiaansch, Spaansch en Portugeesch, en het Latijn in zoover machtig te zijn, dat men in die talen kan lezen. Bovendien moet men dan eenig begrip hebben van Indiaansche en van Afrikaansche talen en van eenige algemeene grammaticale regelen.

Garcia de Horta sprak in 1563 in zijn te Goa verschenen boek al van vijgen uit Guinea, die men bananen noemt. Eerst in den allerlaatsten tijd is vastgesteld, dat de Musa in de Mandingo- en Kmatalen heet: banana, bananda, en bana in het Sierra Leone-gebied. Even wil ik hier tusschen voegen, dat ik het woord bana (voor banaan) zeer duidelijk vernam van een Boschnegerin te ApatoeKondré aan de eerste stroomversnellingen, den Armina-val, van de beneden-Marowijne, in 1894 of 1895 . Dr. Friederici zet dan uiteen, dat de Portugeezen in den tijd, waarin Garcia de Horta schreef, de banaan van de westkust van Afrika, bepaaldelijk van het eiland São Thomé (San Thomé), naar Brazilië hadden gebracht, die daar hadden gekweekt en zeer sterk verbreid. Onder de Indianen van Zuid-Amerika, die onder Portugeeschen invloed in grooten mate het woord banana min of meer verbasterd aannamen - Erland Nordenskiöld geeft veel bijzonderheden op blz. 64-85 van zijn in 1922 te Göteborg uitgegeven boek „Deductions suggested by the geographical distribution of some postcolumbian words used by the Indians of S. America" - treft men behalve het woord vanana ook het woord enguineya als naam van de Musa aan. De Portugeezen hebben hoogstwaarschijnlijk de Musa sapientum, variëteit paradisiaca, van de inlandsche aanplantingen in Guinea uit naar hun plantages op São Thomé overgebracht en ze van hier uit, of wellicht rechtstreeks van Sierra Leone en La Mina uit, overgeplant naar Brazilië, èn naar de Kongo-landen.

Het in de oude berichten voorkomende woord pacova, dat eveneens in Brazilië werd gebezigd, heeft men tot in den allerlaatsten tijd gehouden voor een oud inheemsch Tupi- en Guarani-woord. Meestal trok men dan uit die meening de slotsom, dat de bedoelde Musa-soort voor de ontdekking van Brazilië aldaar reeds van ouds inheemsch was. Maar ook hier is Afrika het land van oorsprong, en alles wijst er op, dat deze naam uit de Kongo-landen kwam. De Nederlander Pieter de Marees, die in het einde van de 16de eeuw in West-Afrika reisde, in de Portugeesche kolonië vertoefde en het eerst in 1602 zijn reisbericht liet drukken, zegt in zijn hoofdstuk „Vande Fruyt Bannanas, of Indische Vyghen” beslist, dat deze vrucht in Guinea Banana in Brazilië Pacoua, door de Nederlanders Bachovens wordt genoemd, en dat deze Pacovas of Banna- 
nas de Congo uit het koninkrijk Kongo zijn gebracht en zoo hun naam hebben gekregen. Dr. F. vindt in het Afrikaansche woord maccobecco de wortel van het braziliaansche paccoba terug. De Portugeezen dreven van het begin van de 16de eeuw af een levendigen handel in slaven en in dieren tusschen Angola en Brazilië. In Loanda of Benguela werd de vrucht reeds met een verbasterden naam verscheept; in Brazilië hebben de Tupis het woord nog meer verbasterd. Naar een bepaalden grammaticalen regel is uit het Kongo-woord maccobecco het Tupi-woord paccoba ontstaan (met den tusschenvorm pacco-becco). De Nederlanders, die jarenlang belangrijke gedeelten van Brazilië bezaten, die ook het koninkrijk Kongo veroverden en jaren in bezit hielden, en een levendigen handel dreven tusschen West-Afrika en Brazilië, hebben in hun reisberichten vooral het woord bakkove voor de banaan gebezigd.

De derde veel omvattende naam voor de Musa in Amerika is plátano of plántano, voor Musa-soorten zonder onderscheid. Bij de eerste ontdekkers, Columbus (Sp. Colón), Las Casas, dr. Chanca, Ferd. Colombo, Petrus Martyr, Amerígo Vespucci, Cabeza de Vaca, Carjaval, e.a., die in den allereersten ontdekkingstijd Spaansch Amerika als nog maagdelijk (onontdekt) gebied het eerst hebben bezocht, vindt men geen woord over de Musa. Eerst na eenige jaren treedt het woord plátano voor Musa in deze gebieden op, ook in vele Indiaansche talen (Nordenskiöld, l.c.). Zoowel uit de berichten en opgaven van Ovíedo y Valdés, als van Alonso de Santa Cruz, Cobo, Acosta en Aguado blijkt, dat naar de meening van de tijdgenooten de Musa oorspronkelijk uit Afrika is gekomen, dat ze van de Spanjaarden verkeerdelijk met den naam van de plataan (Platanus occidentalis) is gedoopt - wie denkt hier niet aan den volkomen onjuisten naam van pine-apple, dien de Engelschen aan de ananas hebben gegeven -- en dat ze onder den naam van plataan omstreeks 1516 van de Canarische eilanden naar Amerika is gebracht.

Toen ik het voorrecht had in 1908 als gedelegeerde der Nederlandsche regeering op het Amerikanisten-Congres te Weenen den heer Ritter Franz von Wieser te ontmoeten (de heer dr. J. D. E. Schmeltz, directeur van 's Rijks Ethnografisch Museum, was toen eveneens vertegenwoordiger van onze regeering) gaf hij mij een exemplaar ten geschenke van zijn kostbaar werk „Die Karten von Amerika in dem Islario General des Alonso de Santa Cruz", Innsbruck, 1908. Daar staat, op fol. 16 van dit boek, waarvan, voor zoover mij bekend, slechts dit eene exemplaar hier te lande aan- 
wezig is: „Traxose assi mismo de la Gran Canaria a esta ysla (d.w.z. Española) un arbol que falsamente se llama platano". Dr. F. haalt dit ook aan.

Ik wil hier ter plaatse nog bijvoegen, dat dr. Friederici in dezelfde aflevering van het in den aanvang aangehaalde tijdschrift nog behandeld heeft de woorden lama, alpaka, guano, jaguar, tapir, opossum, zebra en kautschuk, en in den jaargang 1930, blz. 175-188, vier woorden ontleend aan het Tupí, nl.: ajoupa, boucan, palétuvier en tiburón.

Zelf heb ik het onderwerp behandeld op het in 1924 te Göteborg gehouden Amerikanisten-Congres; zie in het in 1925 aldaar uitgegeven Compte-Rendu mijn artikel „Observations on the name Bacove", blz. 321-333, met de volgende paragrafen: 1. The banana (Musa sapientum L.) ? in the Congo; 2. Plantains and bananas in Guinea; 3. The name bacco as plur. form at home in the interior of Guinea; 4. Quotations from dr. Rung; 5. Schomburgk's evidence; 6. The bacove in French- and Dutch Guinea. Musa paradisiaca named banaan in Surinam. Pacoba and bacoben in dictionaries. Back to Africa; 7. The words bacco, paco, backoh, bacovo, bacove, pacova, pacoba; 8. Veth's opinion; 9. Other sources of information.

Mijn slotsom is, dat voor Musa sapientum de volgende namen bestaan: Port.: baco, paco, pacova; Spaansch: banana, bacova; Engelsch: banana; Fransch Guyana: bacave, bacove; Nederlandsche Zeevaarders en Nederlandsch Guyana: enkelvoud: bacove, meervoud: bacoven, bakkovens; Negerengelsch in Suriname: bakoeba (bakuba); Nederland, officieele stukken: bacove, bacoven; Nederland, het gewone volk: banaan, bananen; Ned. O.Indië: pisang.

Voor Musa paradisiaca zijn de namen de volgende: Port.: banana; Sp.: platano, bacobèn; Eng.: plantain; Ned. Guyana: banaan, bananen; Negerengelsch in Suriname: baäna; Nederland: banaan, bananen; Ned. O.-I. pisang.

Zooals uit het bovenstaande overzichtje blijkt, heb ik getracht de beide variëteiten van Musa goed uit elkander te houden. Trouwens, ieder Surinamer en ook ieder, die Suriname bezocht heeft, zal zich nooit vergissen en kent het verschil. Musa sapientum is de Surinaamsche bacove, een vrucht, een lekkernij; Musa paradisica de Surinaamsche banaan, een groente, die ongekookt niet kan worden genuttigd. Dr. Friederici heeft echter met dit groote praktische verschil geen rekening gehouden. Men begrijpe mij echter wel, met deze opmerking van kritiek bedoel ik niet hem iets van 
de hulde te ontnemen, die zijn prachtig onderzoek verdient. Wanneer de Surinamers doorgaan met den echten oud-Nederlandschen naam van „bacove" te bezigen, onze regeering daarin eveneens blijft volharden, en de beschaafde Nederlanders deze voorbeelden willen volgen, dan komt misschien het voor de bacove-vrucht gedachteloos van de Engelschen nagebauwde woord bananen weer wat op den achtergrond. 